\title{
To the results of the regional study of murders
}

\section{Introduction}

The need for regional studies is determined by the economic and social heterogeneity of the population of different regions of the country, as well as the multidimensional specificity and differentiation of regions. The above said fully apply to the demand for crime research in the regional context. In fact, we are talking about the features of the "flora", "fauna" and "climate" in the region, which together determine the specifics, prevalence and trends in the dynamics and nature of crime, and also affect the state of quality law enforcement activities. Under the "flora", "fauna" and "climate" are understood, respectively, the socio - economic conditions, the specificity of the mentality of the population and the psychological climate in the region. The first of them (the specificity of the region, its "flora" and "climate") are the object of study, while the latter determine its subject area.

The present study is devoted to the analysis of the situation with murders in the North Caucasus Federal District (NCFD), regional specifics of their prevalence and nature, and various aspects of law enforcement practice. His $\mathrm{m}$ etodika included a study of statistical and documentary material, as well as the analysis of the whole array of cases sentences $\mathrm{s}$ of the murder made by North Caucasus Federal District courts in 2013-2016gg. (465 cases); In addition, the indicators of criminal statistics were compared with the data of medical and demographic statistics, with the results of other regional studies of crime and mortality from external causes, as well as with the results of the study of the death rate from murders in Russia for 1956-2014.

The initial stage of the study was based on several diverse but somehow interrelated working hypotheses. Based on the heightened terrorist background and statistically significant manifestations of extremism in the region, the first of these hypotheses concerned a significant (perhaps higher than the official statistics) of the prevalence of murders, as well as the region-specific nature of these manifestations (peculiarities of the formation of criminal intent, its orientation, methods of implementation, severity of consequences, etc.).

The second hypothesis, based on specific social, economic, cultural, ethical, religious and other conditions and factors of the region's development, was associated with a higher level of murder latency than in other regions and the presence of specific factors forming this latency.

Finally, the third of the main hypotheses was based on the assumption of a more liberal practice than in other regions and the country as a whole in the imposition of punishment for murders, as well as on the specific shortcomings in law enforcement related to the unjustified qualification of these crimes during the investigation.

Without claiming for a complete and indisputable nature of judgments, let us consider the results of the analysis performed through the prism of these hypotheses; such an analysis makes it possible to introduce in the initial representations certain refinements and corrections that are significant in scientific and practical terms.

To begin with, let's outline the main specific features of the region. In the federal system of the country, the NCFD is a relatively young

\author{
Volume 2 Issue 5 - 2018 \\ Vitaly Y Kvashis \\ Honored Scientist of Russia, Russia
}

Correspondence: Vitaly Y Kvashis, Honored Scientist of Russia, Russia, Email: kvashis@mail.ru

Received: August 0I, 2018| Published: September 20, 2018

structural entity formed in 2010. The SKFO accounts for only $1 \%$ of the territory, but its population is $7 \%$ of the total population of the country. This fact in itself speaks of the importance of the region in the system of the state system of Russia. The NCFD, in fact, the region in a number of relations (geopolitical, economic, cultural, etc.) is extremely important and at the same time very specific and rather complicated.

Uneven settlement and distribution of the population of Russia through its territory occurred, as is known, under the influence of historical, political and other factors, which led to multifaceted territorial differences. This is also confirmed by the modern differentiation of regions in terms of socio-economic, demographic and many other parameters (including regional differentiation of crime, prevalence of violence, etc.). In the regional formations formed as a result of such settlement, the high degree of ethno-linguistic, religious and cultural heterogeneity that promotes competition and conflicts between different ethnic and other social groups is differently manifested. In this respect, attention is drawn to the dynamics of a consistent reduction in the Russian population in the national republics of the region (over the last 30 years, it has decreased by an average of $20 \%$ ).

In the NCFD, due to its multinational composition, linguistic, ethnic, cultural and other heterogeneity of the population, there is a peculiar system of traditions, customs and behaviors that have developed in specific cultural and historical conditions and reflect the experience of social interaction accumulated by generations, traditional values and forms of perception of the world. Moreover, such diversity and specificity are manifested even within a particular component of the region. Take, for example, Dagestan, where the problem of decriminalization of society today is most acute. Dagestan is the largest republic in terms of population (more than 3 million people or one third of the population of the North Caucasus Federal District), in which dozens of different linguistic and ethnic groups exist. The influence of the rigid estate hierarchy, stable ethnic communities and clans is especially noticeable here. In fact, this is a traditional society, where along with the law no less important is based on customs and traditions specific general and political culture.

The defining features of the identity and mentality of the peoples inhabiting the NCFD are group generality, subordination 
and dependence on the group, the dominance of vertical ties of generations, strict hierarchy, unconditional submission and devotion to the leader. Along with socio-economic, organizational, managerial, legal and other factors, these considerations cannot be ignored when assessing the criminal situation in the region.

As in other regions of the country, in the North Caucasus Federal District the main socio-economic situation is a critical factor, characterized by a low standard of living for the majority of the population and a high level of unemployment. According to Rosstat data for 2016, in Ingushetia, for example, $32 \%$ of the population has incomes below the subsistence level; in KabardinoBalkaria and Karachaevo-Cherkessia every fourth inhabitant refers to a category that social statistics refers to as "poverty". In the State Program "Development of the North-Caucasian Federal District for the period until 2025" adopted in 2014, it was noted that socioeconomic problems are extremely acute in the region as a whole and especially in the republics of North Alania and Dagestan; they serve as a fertile ground for involving unemployed people and low-income citizens in the antisocial sphere. Despite the measures taken, Dagestan remains one of the most labor-surplus regions, where the growth of labor resources continues, outpacing the number of jobs created. Against this background, the greatest danger is the involvement of the unemployed youth in the criminal sphere.

The unfavorable criminological situation, which unfolds on such a background, contributes to the formation of a number of mythological ideas and stereotypes concerning the typology of the "Caucasian" criminal and much more than, in fact, the prevalence of crimes (including murders) in the national republics of the region in the public consciousness of Russians. Another myth is the widespread belief that almost all the inhabitants of the NCFD are Muslims and in their criminal behavior extremist or terrorist motives always dominate. In fact, both do not correspond to the real state of affairs. Firstly, Muslims on the territory of the district make up not more than $50 \%-55 \%$ of the population (the rest profess Christianity). Second, for all ethnic conflicts and emerging on the basis of their acute conflicts, illegal behavior is destructive-minded young people in the region do not actually goes beyond the "consumer nationalism." Meanwhile, against the background of an unfavorable economic situation, attempts to transfer hooligan actions of youth and domestic crimes to the level of interethnic conflicts and to place them in an interconfessional context. The task of the authorities is to resolutely suppress such attempts, especially since in absolute terms these conflicts do not actually go beyond the limits of domestic law and, as the study has confirmed, they are mainly of a domestic nature.

The notion of the high prevalence of "Caucasian" murders in the mass consciousness of Russian citizens requires more detailed analysis. To this end, during the study, the indicators of criminal statistics were compared with the data of medical and demographic statistics, materials of the prosecutor's office and other authorities, with the results of other studies of the regional prevalence of crime and mortality from external causes, as well as with the results of the Higher School of Economics (HSE) HSE studies of deaths from murders in Russia for 1956-2014gg. In the course of this study, it was established that in the structure of mortality from external causes, murders are one of the leading places. Over 60 years in Russia registered 1.14 million. Deaths from murders, representing $9 \%$ of deaths from external causes and 9 times higher than those in the UK and other European countries. ${ }^{1}$ As a result of a consistent reduction in deaths from murders in 2002-2014. Russia returned to the indicators of the late 1980s, but the gap with other countries remains significant.

In the context of our study, the most important are the regional differences. And here we cannot do without a detailed analysis of mortality, especially since the regional differentiation of mortality gives an answer to the question of the contribution of the region to the overall mortality rate from murders. To this end, the HSE study clustered 83 regions of Russia based on the average value of the standardized death rate, where all regions were divided into 4 clusters (K). The study showed that in the regions of the North Caucasus and South-West Russia (K1), the average value of the male death rate from murders from 1992 to 2010. In the calculation for 100 thousand people is from 11 to 25.49 . For comparison, in regions $\mathrm{K} 2$-this indicator is from 25.49 to 34.59 ; in $\mathrm{K} 3$-from 34.59 to 47.23 ; in $\mathrm{K} 4$-from 47.23 to 199.30 . As can be seen, the prevalence of deaths from murders in the North Caucasus Federal District by the time of its formation was the least compared to other regions of the country. In particular, it is three times lower than in the cluster K-3 (North-West regions, as well as regions of Western Siberia) and seven times lower than in the regions of cluster K-4 (Eastern Siberia and the Far East). The different death rates from homicides and the rate of their changes in a given region indicate different responses of the population of these regions to socio-economic processes during different periods of the country's development; in particular, the population of regions classified as K-4 reacted to certain social shocks more than others.

Let us now turn to the criminal statistics that characterize the prevalence of murders in the North Caucasus Federal District. In 2014, 471 murders were recorded in this region, half of which are in equal parts in Stavropol and Dagestan; the murder rate in the region was 4.9, which are 6-7 times higher than, for example, in Germany and 12 times higher than in Japan. ${ }^{2}$ In 2017, the situation with murders in the North Caucasus Federal District has changed dramatically: in Dagestan, their number has fallen from 148 to 71 in three years; in the Stavropol Territory-from 146 to 121; in Kabardino-Balkaria-from 44 to 26; in the RSOA from 34 to 11; in the KCR-from 50 to 30 . The overall decrease in the number of murders in the region for three years was $35 \%$ (from 471 to 309 ), and the murder rate decreased by $36.7 \%$ (from 4.9 to 3.1). It should be noted that this transformation in the region is taking place against the backdrop of a long-term reduction in murders in the country as a whole, but since we are comparing the situation in 2014-2017, it is important to point out that the scale and rate of such decline in the NCFD were twice as high as in the country in general (from 11,933 to 9,740 or $18.4 \%$ ). This is, undoubtedly, a very positive phenomenon; it corresponds to the worldwide trend of decreasing homicides, although there is as yet no acceptable explanation for it either in criminology or in sociology, which fixes all new social diseases and the overall worsening of the socioeconomic situation.

However, such a rapid statistical decrease in the total number and level of murders in the region, hardly corresponds to the real state of things. At the same time, our a priori doubts about the authenticity of the statistical picture are based not only on the long experience of analytical work and the experience of a number of parallel studies, which for the hundredth time confirms that there is a lie and there ${ }^{1}$ Vishnevsky AG. Mortality from external causes in Russia since the midtwentieth century. M Higher School of Economics, 2017.

${ }^{2}$ Kvashis VE, Henrikh NV. Comparative analysis of crime, criminal policy and law enforcement practice in Russia and Japan. Society and Law. 2016:2. 
are statistics, but also other regional factology; in different ways, it directly or indirectly indicates that in fact the situation with murders in the region is not quite this or, rather, not at all like that. In the subsequent presentation, we will return to these doubts, but for the time being we point out the following arguments, which relate primarily to the situation in such republics of the North Caucasus Federal District as Dagestan, Ingushetia and Chechnya.

Long-term observations of researchers show that, as a rule, a normal statistical picture and a common trend for the country reflect the ratio of the number of murders and the number of intentional causing of serious harm to the health of victims. Normally it looks like 1: 2. However, in Dagestan, for example, it was: in 2014-148: 119; in 2015 -111: 113; in 2016, -104: 89. Accordingly, in Ingushetia, this attitude looks like this: $20: 12 ; 18: 19 ; 16: 11$; but in Chechnya, which is a "state in the state" and is therefore often called the sultanate, 29:14; $39: 11 ; 26: 13$. This paradoxical deviation from the general trend (more precisely, the inverse pattern) is "pathology in the norm"; it, to put it mildly, raises serious doubts about the reliability of statistics of a number of regional subjects. The above average murder rate in the region as a whole (3.1 in 2017), in fact, does not reflect even the "average temperature of patients in the hospital." In Chechnya, for example, where the entire population has firearms, the murder rate is 1.8; As for Dagestan, according to the number of crimes with the use of firearms, this republic takes the first place from year to year. Shooting for any minor incident here is the usual modus operandi. Knowing about the mass practice of refusals to initiate criminal proceedings, about the existing fees for such decisions, etc., one must be very naive in order to believe the statistical texture...

All these "details" of the general picture, one way or another, do not abolish the tendency noted above to reduce the number of murders (both in the country and in the region). If all this is at least a "part of the truth," the regional specifics of such a trend in the NCFD, among other things, is related, in our opinion, to two, perhaps, leading factors. The first of these is likely to be associated with the highest rates of forced (due to unemployment and low living standards) migration of young people to large urban centers of Russia. The decrease in the share of the youth cohort in the population structure, as is known, always contributes to a general decrease in crime. Secondly, and this is taking place against the background of the influence of the first factor, in a region with a strong generic and communal structure, a certain reassessment of values takes place, including the values of human life, when the violent forms of conflict resolution are replaced by an awareness of their preferred solution through reconciliation and agreement of the parties with simultaneous compensation for physical or moral harm caused to the victim. In other words, under the influence of the community, family clans and their leaders, the resolution of conflicts is gradually moving from violent to "economic" rails, and violence itself, especially in such extreme forms as murder, is becoming increasingly odious and, most importantly, " unprofitable ". 3 Once again, this explanation is, firstly, only one of the possible versions of the ongoing transformation and, secondly, it is related specifically to the specifics of the way of social life in this region.

There is another factor that influences this trend to reduce the prevalence of murders; partly it has already been mentioned, but it is extremely important, although it is not conditioned by regional specifics. It should be borne in mind that the earlier idea of the insignificant latency of murders, long ago, as numerous studies have shown, is a thing of the past. Moreover, the number of murders ${ }^{3}$ Kvashis V. Regional features of murders: prevalence, nature, law enforcement practice. Criminal Law. 2018. recorded by statistics is only the lowest limit of their real estimate and, moreover, the estimates of the number of dead. Here it should be noted that, for obvious reasons, the indicators of the medical mortality statistics from murders and criminal statistics do not coincide and cannot coincide. Suffice it to say that in the country as a whole, about $10 \%$ of registered murders accounted for the share of assassinations (in the North Caucasus Federal District-14\%). Obviously, mortality statistics from murders will always provide lower values (than in criminal statistics). The main thing, however, is not in the level of these discrepancies, but in the difference between the real and legal (registered) number of murders; this difference is the problem of the latency of murders.

The methods of various manipulations with the statistics of murders have long been well known (the growth of the number of unidentified corpses or corpses with an unidentified cause of death, an increase in the number of missing persons and persons under search, etc.). It was investigated in this connection that if we assume that only half of this number of people died or were missing as a result of violent death, the killings will double; If, on the other hand, it is taken into account that only two thirds of the murderers are identified and condemned, it turns out that on average, responsibility is only for every second murder. ${ }^{4}$ The results of our studies confirmed the validity of this assumption; according to our calculations, the actual number of murders in Russia by the end of the first decade of the 21 st century was 2.5 times higher than official data.

If we turn to the world practice of registering and recording murders, then the wiles of domestic statistics will become even more obvious. The fact is that in international documents dealing with the order of statistical recording of crimes, and in the registration practice of many countries, murders are treated more broadly; "Murder means" the deliberate infliction of physical harm to a person, which caused his death." In Russia, however, only intentional infliction of death on another person (Article 105 of the Criminal Code of the Russian Federation) is referred to the category of "murder", and such acts as deliberate infliction of grievous harm, which resulted in death through negligence, infanticide, rape that resulted in death, and other types of actual murder, in the statistics of murders do not fall. As a result of various manipulations with registration and a number of legal "nuances" The real picture of murders in the Russian Federation has long been considered to be significantly understated.

The significance of such an indicator as the number of persons missing is already mentioned; According to the Institute of Problems of Law Enforcement, in the last two years the police recorded more than 34 thousand applications from citizens with such statements. The named indicator is one of the main markers of murders. The same can be said about unidentified labor. P on the media reports, every year in Russia goes missing and 120 thousand people; for 2009-2015. 72 thousand unidentified corpses were found. ${ }^{6}$ A comparison of all these figures of the answer to the question of the real number of murders cannot give ; it resembles an anecdotal problem with the number of cars in the train, the seats in each car and the final question - how to call the machinist?. The only answer to this question can be the statement that the real number of murders is known and significantly higher than the number of recorded murders. The most correct explanation of this

${ }^{4}$ Repetskaya A, Bogdanov SV. Murders in Russia and the United States: A Comparative Analysis of Criminal Statistics. Criminological Journal of the Baikal University. 2009:4.

${ }^{5}$ Kvashis VV. The death penalty. World tendencies, problems and prospects. Yurayt M, editor. 2008. p. 546-548.

${ }^{6}$ Version, No. 16, April 23, 2018. 
picture boils down to the fact that in reality, at least the murders do not decrease, but not all of them (and not always in a timely manner) are registered and. therefore, do not fall into statistics.

For comparative analysis, it is important to keep in mind that in a number of countries the number of murders is fixed not by the number of episodes, as in Russia, but by the number of people killed (in a single episode, several people may be killed, but one murder is recorded ). In addition, in the UK, for example, the number of dead and the number of murders are much more divergent due to the fact that for various reasons ( killing of murder, prompt medical assistance, etc.), 35\% to $50 \%$ of the victims succeed to save and such assassination attempts in statistics of murders (unlike Russia) are taken into account separately. Accordingly, the murder detection agents are also changing.

All this, of course, goes far beyond the scope of regional crime, but it allows us to pose the question more broadly: if all sorts of manipulations are possible, even with statistics of murders, is it any wonder that per capita the number of crimes registered in Russia is five times less, than in Germany? (in 2017, 2.068 million were registered in Russia, and 5.76 million crimes in Germany, respectively, the population was 143.4 million and 82.8 million people). The answer to this question is related not only to the practice of responding to citizen communications and registering crimes. Among other things, it means that the police (read-vlast) bad imagine the real picture of crime and, and, most importantly, does not really want to know about the realities.

For the sake of fairness, we note that the NCFD takes measures to ensure the reliability of criminal statistics and control over the practice of registration and recording of crimes. In Dagestan, for example, the prosecutor's office's examination of documents on the initial recording of crime reports found that the most common violations are still distortions of information about crimes in public places (they are understated by a factor of 3 ), and data on crimes committed in a state of intoxication are understated in 11 times. $^{7}$ The absence of due account for such information in the region is confirmed by our research. At the same time, it is important to bear in mind that the formation of latent crime is influenced by the fact that in the republics of the district the local population increasingly prefers to resolve interpersonal conflicts on their own, within communities, clans and teips, trying to exclude or minimize the participation of authorities in them as much as possible.

The trend towards an increase in the conflicts so resolved in the North Caucasus Federal District is becoming increasingly noticeable. This is not an accidental phenomenon; in ethnic republics ethnic, religious and community-tribal factors formed the basis of an informal system of social control. These circumstances should be taken into account in the general assessment of the state of crime, and in analyzing the latency of certain crimes. The practice of registering and recording murders in this regard is no exception.

Summing up this part of the study, we can draw two main conclusions. According to official statistics, the first of them, contrary to the original hypothesis, is that the prevalence of murders in the NCFD is characterized by indicators that are the least in comparison with neighboring regions, and, especially, for the country as a whole. At the same time, the scale and rate of reduction of murders in the region over the past three years turned out to be twice as high as in the country as a whole. As for latency kills, the feature of the region is its formation is mainly due to improper qualification of the offense investigation bodies (mainly floor of concerns attempted murder)

${ }^{7}$ The site of the Prosecutor General's Office R.F. URL: https://genproc.gov.en / smi / nevs / regionalnews / news -591229 /
Another conclusion is connected with the need for a substantial correction of the statistics, for the real picture of the murders still remains terra incognito.

The second working hypothesis concerning the specific nature of the murders in the North Caucasus Federal District was not confirmed in the course of the study. Contrary to the prevailing notions, in the general array of cases studied there were not a single murder with a "Caucasian" coloring, as well as cases with motivation of a terrorist or extremist nature. In $98 \%$ of the cases of murders, there are the most banal crimes of domestic character, not related to "domestic nationalism". This is mainly situational, crimes committed during drinking alcohol on the basis of quarrels with neighbors, acquaintances or close relatives; at the same time, more often than not, the perpetrators themselves reported the committed acts (in many respects, from this, the high rates of murder detection).

Household crimes are in many respects a paradoxical criminal manifestation: they are committed in the familiar surroundings, almost never unexpected, criminals and victims know each other well and are often related and related; while the severity of the consequences is often directly proportional to the degree of proximity of criminals and victims. Such crimes do not pursue any rational goals; as a rule, they lack preparatory activities and concealment; they are easily predictable, do not pose a problem for disclosure, but are not timely notified.

About $10 \%$ of the perpetrators of the murders are women; in $14 \%$ of cases there is an attempt on murder; in $85 \%$ of cases, the perpetrators were not previously convicted. Such crimes were more often spontaneous in nature and, as a rule, were provoked by insults or other unlawful actions of the victims themselves.

As in crime in general, in the sphere of domestic crimes, there are quantitative and qualitative changes. Marked weakening of social control in the manufacturing sector and in the home, stratification of the population by socio-economic status, unemployment, the deformation of the system of social values it, the depreciation of the family institution, etc. All this affects the criminological characteristics and trends in household crime.

On the domestic character of the studied acts, in addition to other features of the situation, evidence of the tools of murders also testify. In the vast majority of cases, murders were committed by kitchen knives or penknives and only $2 \%$ of the cases were guns that were violated (such a pattern is formed by the verdicts of the court, it is clear that there are a lot of unregistered facts of using the weapon behind it). One way or another, in the preventive activities of the entire system of government authorities should significantly strengthen control over the behavior of people in the domestic sphere.

Against the background of this general picture, its details and characteristics are typical, characterizing the characteristics of the various categories of victims of murders; this typology allows us to extend to them the typical risk factors identified in the analysis of mortality from external causes. ${ }^{8}$ These factors are typical for the country as a whole and it is no accident that they dominate the NCFD. These include:

a) Age and gender factors (the main array of victims is people of working age, the share of deaths in people over 60 years old is only $4 \%$ among men and $4.9 \%$ among women, as the age increases, the death rate as a result of murders among the elderly is growing, which is associated with the characteristic

${ }^{8}$ Vishnevsky AG. Mortality from external causes in Russia since the midtwentieth century. M. HSE; 2017:224-228. 
for them increased victimization ). Therefore, pre- empting violence against older people should become one of the areas of preventive action ;

b) Urbanization and population density (the risks are growing amid increased migration from rural to urban areas, due to high unemployment, poverty and difficulties in integrating rural people into the urban environment);

c) Social and property inequality (it creates and maintains tension in relations and engenders conflicts);

d) Ethno-linguistic and religious heterogeneity (in the NCFD, the influence of this factor is particularly palpable-the interaction of heterogeneous social groups contributes to the growth of the number of conflicts);

e) Alcohol abuse (the contribution of alcohol to violent deaths is dominant, alcohol is the source of aggression in most crimes against the individual, while alcohol consumption falls during economic recovery and increases during the economic downturn).

In all of these risk factors are interrelated. The multiplicity of socioeconomic, demographic, geographical and other risk factors and their close relationship make prevention of homicides a complex problem. Victim logical prevention of various forms of violence, taking into account the specificity of domestic crimes, and, most importantly, vulnerability, features of behavior, status and other specific qualities of potential victims, is of particular importance.

Finally, let us turn to the last hypothesis of our study. Recall that initially it was assumed that there were specific features of investigative and judicial practice that absorbed and relied on specific features of the region and the criminal situation that developed in it. The peculiarities of prevalence and the dominant character of domestic crime in the North Caucasus Federal District in a certain measure could be reflected in the practice of imposing punishment for murder. However, a comparison of the average sentence in the North Caucasus Federal District with the data of the federal judicial statistics, as well as with the results of other regional studies, showed that there is no special specificity here either; they are generally identical to the existing practice in the country of sentencing and coo tvetstvuyut recommendations riding vnogo Court of the Russian Federation. At the same time, the criminal legislation as a whole and the sanction of Art. 105 of the Criminal Code leave a certain gap for law enforcement at the level of a specific criminal case. In summary , the sentences prescribed by the courts allow us to talk about certain trends, about a certain orientation of judicial practice in choosing the punishment in the "corridor" established by the criminal law, and in this case, within the sanctions of Art. 105 of the Criminal Code. From this point of view, the following conclusions can be drawn.

First, the trend associated with the consecutive rejection of judicial practice from the imposition of sentences in the form of a conditional conviction for an assassination attempt is becoming more and more evident. A bolsolitizatsiya this line is strengthened against the comparison of the average sentence for an attempt (6 years) and punishment for a "simple" murder-Part 1 of Art. 105 of the Criminal Code ( 8 years). It turns out that the judicial practice in selecting the penalty is a significant difference between the attempted murder and murder, or does not see, or takes it into account in full.

Secondly, at both the regional and federal levels, the practice of punishment for murder is mainly oriented either to the minimum limits of the sanction of Part 1 of Art. 105 of the Criminal Code or on the average size of the sanctions provided for by Part 2 of Art. 105 of the Criminal Code (murder under aggravating circumstances), all less often applying in the latter case of punishment for a period of 10 to 15 years. In this regard, the average term of the penalties imposed by the courts of the North-Caucasian Federal District for the qualified murder (14 years) should be considered quite justified, especially since the judicial practice in these cases is more focused on taking into account circumstances that reduce responsibility.

At the same time, regional practice of differentiating punishments in the framework of sanctions Part 2 of Art. 105 of the Criminal Code in the NCFD has its own nuances in relation to various aggravating circumstances. If the average term of punishment (14 years) in case of murder committed by a group of persons by prior conspiracy ( item "f" part 2 of Article 105 of the Criminal Code ), one can recognize the craving for the fathers to average ("normal") values, the practice of imposing punishment on item " 3 " Part 2 of Art. 105 CC, where the average term is 9 years, it is difficult to recognize justified, because it is about the most dangerous selfish violent crimes (murder with penetration into a dwelling with the purpose of robbery). Such a measure, in our view, is excessively liberal, if you will homoeopathic, not adequately assessing the social danger of the crime and not corresponding even to the average value of the sanction and the norm provided for in the law. In the United States, for example, killing with selfish motives, especially when coupled with penetration into the home and robbery, entails a penalty of imprisonment for up to 25 years, and in Japan, where the selfish motivation for murder is considered an aggravating circumstance, a lifelong deprivation of liberty or the death penalty.

Finally, the effectiveness of the regional (and federal) practice of imposing additional punishment for killing in the form of restriction of freedom for one year after serving a long $(12,15,19$ years) prison term is, in our view, questionable; the preventive role of this measure at the time of sentencing is clearly overestimated and therefore such decisions are of a formal nature. They would be much more relevant and relevant, for example, when a court appoints such a restriction, deciding the issue of parole.

In general, the regional judicial practice correctly assesses the public danger of the offense and the identity of the perpetrators, while eliminating the errors of the investigative authorities related to the re-qualification of crimes (from Article 105 of the Criminal Code at Article 107, 107, 109,111, 114, 115, 119 of the Criminal Code of the Russian Federation ). In this case, it is, more often than not, the question of turning the fiction of assassination attempts. The changes in the qualification of the deed, by the way, change the statistical picture of the murders.

Among the most typical mistakes of regional investigative bodies are: the wrong delineation of murders with indirect intent and causing death by negligence; lack of understanding of the boundaries between the attempted murder, the threat of murder and deliberate infliction of serious harm to health; There is also a unified position of the judicial and investigative authorities regarding the assessment of the state of affect.

\section{Acknowledgements}

None.

\section{Conflict of interest}

Author declares there is no conflict of interest. 